\title{
Green synthesized Zinc Oxide Nanoparticles Elicited a Prominent Suppression of Oxidative and Inflammatory Distortions in Rats Exposed to Carbon Tetrachloride
}

\author{
Chiagoziem A. Otuechere ${ }^{1, *}$, Adewale Adewuyi ${ }^{2}$, Adriel Ekozin ${ }^{3}$, Xiao Feng ${ }^{4}$, , Franco M. \\ Cabrerizo 5 (D)
}

1 Department of Biochemistry, Redeemer's University, Ede, Osun State, Nigeria; goziemo12@yahoo.com (C.A.O.);

2 Department of Chemical Sciences, Redeemer's University, Ede, Osun State, Nigeria; walexy62@ yahoo.com (A.A.);

3 Department of Biochemistry, Redeemer's University, Ede, Osun State, Nigeria; ekozinadriel@ymail.com (A.E.);

4 State Key Laboratory of Aquatic Chemistry, Research Center for Eco-Environmental Sciences, Chinese Academy Sciences, Beijing, China; fengxiao@rcees.ac.cn (X.F.);

5 Chascomus Institute of Technology, National University of General San Martin, Buenos Aires, Argentina; fcabrerizo@hotmail.com (F.M.C.);

* Correspondence: goziemo12@yahoo.com (C.A.O.);

Scopus Author ID 55414500800

Received: 1.07.2021; Revised: 25.08.2021; Accepted: 1.09.2021; Published: 18.10.2021

\begin{abstract}
This study centered on Zinc oxide nanoparticles capped with Pterocarpus mildbraedii leaf extracts (PmZnONPs) as a potent antioxidant and anti-inflammatory agent against carbon tetrachloride $\left(\mathrm{CCl}_{4}\right)$ - induced hepatorenal toxicity in rats. PmZnONPs were characterized by Fourier transform infrared spectroscopy (FTIR), Brunauer-Emmett-Teller (BET), scanning electron microscopy (SEM), X-ray diffraction pattern (XRD), and transmission electron microscopy (TEM) techniques. The FTIR results revealed the presence of various functional groups in PmZnONPs, while the BET showed a surface area of 1.55 mg-2. In vitro, PmZnONPS showed comparable 1,1-diphenyl-2-picrylhydrazyl (DPPH), and 2,2'-azino-bis(3ethylbenzothiazoline-6-sulfonic acid (ABTS) radicals scavenging activities as Vitamin C. After that, PmZnONPs (1 and 3 $\mathrm{mg} / \mathrm{kg}$ ) were administered (p.o.) into six groups of rats, using $\mathrm{CCl}_{4}$ as the toxicant. The obtained results demonstrated that PmZnONPS significantly prevented $\mathrm{CCl}_{4}$-induced elevations of alanine aminotransferase (ALT), aspartate aminotransferase (AST), gamma-glutamyl transferase (GGT), alkaline phosphatase (ALP), bilirubin (BIL), creatinine, and urea. Moreover, PmZnONPs restored the levels of plasma uric acid, hepatorenal antioxidant enzymes, including superoxide dismutase, glutathione peroxidase, glutathione transferase, and glutathione that were significantly decreased by $\mathrm{CCl}_{4}$ treatment. Immunohistochemical studies showed that PmZnONPs significantly suppressed the high immunoreactivity of nuclear factor kappa B (NF-кB), cyclooxygenase-2 (COX-2), and interleukin-6 (IL-6) arising from CCl4 intoxication. Thus our data hint that PmZnONPs suppressed $\mathrm{CCl}_{4}$-induced toxicity in the liver and kidney of rats via its combined antioxidant and antiinflammatory properties.
\end{abstract}

Keywords: Pterocarpus mildbraedii; green chemistry; inflammation; hepato-renal system; immunohistochemistry; carbon tetrachloride.

(C) 2021 by the authors. This article is an open-access article distributed under the terms and conditions of the Creative
Commons Attribution (CC BY) license (https://creativecommons.org/licenses/by/4.0/).

\section{Introduction}

Organ injuries arising from exposure to environmental chemicals have continued to agitate stakeholders in the public health sector. Due to their involvement in detoxification and metabolism of xenobiotics, the liver and kidney are among the most vulnerable organs to toxic challenge [1]. Organ damage has been recognized as one of the factors that complicate clinical diagnosis and treatment. For example, it had been suggested that underlying liver and kidney injury impaired the disposition of drugs, and by extension, the attainment of therapeutic doses of the drugs, thereby increasing the risk of adverse drug reactions in COVID-19 patients [2]. 
Under the Toxic Substances Control Act, the United States Environmental Protection Agency (EPA) has listed several new and existing chemicals for risk appraisal to determine their toxic threats to human health and the environment. Carbon tetrachloride $\left(\mathrm{CCl}_{4}\right)$, alongside methylene chloride, trichloroethylene, perchloroethylene, asbestos, and 1-bromopropane, are included in this list [3]. $\mathrm{CCl}_{4}$, widely used in the dry-cleaning industry, is also a by-product during the industrial production of chloromethanes and perchloroethylene [4]. Rodent models have been used as a fitting and popular model to study $\mathrm{CCl}_{4}$-induced hepatorenal toxicity in hamsters [5], mice [6], and rats [7]. In rodent liver and kidney, the metabolism of $\mathrm{CCl}_{4}$ is a classic example of bioactivation by CYP2E1, a member of the cytochrome P450 superfamily, to yield the trichloromethyl radical. The trichloromethyl radical can either form phosgene via oxygenation or cause lipid peroxidation via the formation of fatty acid radicals [8].

Oxido-inflammatory stress has long been associated with the etiology of different liver and kidney ailments. Deploying a varied feedback sequence, accumulated free radicals could activate transcription factors such as nuclear factor-kappa B (NF- $\mathrm{BB})$, leading to an inflammatory response via the recruitment of phagocytic leukocytes and induction of downstream inflammatory mediators such as COX-2 and IL-6 [9,10]. It is, therefore, logical that agents capable of blocking these redox and inflammation pathways could attenuate chemically-induced hepato-renal toxicity.

Recently, adopting eco-friendly protocols to synthesize a wide range of nanoparticles and hybrid materials has become more popular [11]. Our previous studies reported the synthesis of nanocellulose from cotton seeds [12] and the preparation of a vermiculite-cellulose bionanocomposite using green synthesis protocols [13]. Likewise, Zinc oxide nanoparticles synthesized from plant metabolites showed antimicrobial [14], mosquitocidal [15], and anticancer [16] activities. In this study, we have used leaves from the medicinal plant Pterocarpus mildbraedii, as the reducing agent in the synthesis of Zinc oxide nanoparticles (PmZnONPs). Previously, the potency of $P$. mildbraedii extract to alleviate chemicallyinduced hepatotoxicity in rats via anti-apoptotic mechanisms and repression of inflammatory stress responses has been reported in our laboratories [17,18]. Hence this study sought to elucidate the mechanisms of the therapeutic efficacy of nanosized Zinc oxide capped with $P$. mildbraedii (PmZnONPs) through a comprehensive assessment of blood chemistry, hepatorenal antioxidant defense markers, and expressions of inflammatory proteins NF- $\kappa \mathrm{B}, \mathrm{COX}-2$, and IL-6.

\section{Materials and Methods}

Pterocarpus mildbraedii leaves obtained from a local market were identified at the Department of Biological Sciences, Redeemers University, Ede, Osun State, Nigeria. 1,1 Diphenyl- $\beta$-picrylhydrazyl (DPPH), 2,2'-azinobis(3-ethylbenzthiazoline-6-sulfonic acid) (ABTS), methanol, $\mathrm{ZnO}, \mathrm{NaOH}$, thiobarbituric acid (TBA), and trichloroacetic acid were purchased from Sigma-Aldrich (St. Louis, MO, United States). Other chemicals used were of analytical grade.

\subsection{Preparation of Pterocarpus mildbraedii extract.}

Pterocarpus mildbraedii leaves (100 g) were extracted with methanol in a soxhlet extractor for $6 \mathrm{~h}$. Excess methanol was removed from the extract in a rotary evaporator. The extract obtained was dried in an oven at $50^{\circ} \mathrm{C}$ for $12 \mathrm{~h}$. 
2.2. Synthesis of PmZnONPs.

Pterocarpus mildbraedii extract was used in preparing PmZnONPs. Briefly, 0.5 M ZnO was prepared in $\mathrm{NaOH}$ solution $(0.1 \mathrm{M})$ and warmed slightly at $70 \mathrm{oC}$ under continuous stirring for $30 \mathrm{~min}$. Approximately $2.0 \mathrm{~g}$ of Pterocarpus mildbraedii extract was added to $50.0 \mathrm{~mL}$ of $0.5 \mathrm{M} \mathrm{ZnO}$ and stirred continuously at $70{ }^{\circ} \mathrm{C}$ for $3 \mathrm{~h}$. The mixture was cooled to room temperature, filtered, washed severally with water, and filtrate dried overnight in the oven at $105^{\circ} \mathrm{C}$.

\subsection{Characterization of PmZnONPs.}

The functional groups in PmZnONPs were determined using Fourier transform infrared (FTIR; Perkin Elmer, spectrum RXI 83303). A particle sizing instrument (Malvern, Mastersizer 2000) was used to determine the particle size (PS), while surface morphological characteristics were confirmed using a transmission electron microscope (TEM, Hitachi H7500) and scanning electron microscope (FE-SEM, Hitachi SU-8020). The Brunauer-EmmettTeller (BET) surface area was determined using a physisorption instrument (Micromeritics Instrument Corp, ASAP 2460), and an X-ray diffraction pattern was acquired on a Rigoku SmartLab with $\mathrm{Cu} \mathrm{K} \alpha$ radiation $(\lambda=1.5406 \AA)$ operating at $40 \mathrm{kV}$ and $150 \mathrm{~mA}$ over a $2 \theta$ range of $5-90^{\circ}$.

\subsection{In vitro antioxidant assays.}

The antioxidant potential of PmZnONPS was evaluated by determining its DPPH and ABTS radicals scavenging abilities. The DPPH assay was performed as previously described [19]. Briefly, $1 \mathrm{~mL}$ was added to samples of PmZnONPs, and Vitamin $\mathrm{C}$ was prepared in triplicates at concentrations of between $50-500 \mu \mathrm{g} / \mathrm{mL}$. The reaction mixture was then incubated in the dark for $30 \mathrm{~min}$, and the absorbance was determined at $517 \mathrm{~nm}$. The $\%$ antioxidant activity was estimated against the control. For the determination of ABTS radical scavenging ability, an equimolar volume of ABTS $(7 \mathrm{mM})$ and potassium persulfate $(2.45 \mathrm{mM})$ was prepared, kept in the dark for $24 \mathrm{~h}$, and diluted in methanol. Subsequently, $20 \mu \mathrm{L}$ of PmZnONPs and Vitamin C $(50-500 \mu \mathrm{g} / \mathrm{mL})$ were incubated with $2 \mathrm{~mL}$ of ABTS+ solution at $30{ }^{\circ} \mathrm{C}$ for $10 \mathrm{~min}$, and absorbance was read at $734 \mathrm{~nm}$. The $\%$ ABTS scavenging activity was calculated against the control [20].

\subsection{Animal model and care.}

Thirty-six male Wistar rats (8 weeks old) weighing between 160 and $190 \mathrm{~g}$ obtained from the Redeemer's University Animal House Facility, Osun State, Nigeria, were used for this investigation. The rats were housed in stainless cages placed in a well-ventilated vivarium at temperatures maintained at $25( \pm 2){ }^{\circ} \mathrm{C}$, under standard laboratory conditions of a $12 \mathrm{~h} / 12 \mathrm{~h}$ light/dark cycle. The male Wistar rats were fed on a commercial pelleted diet (Ladokun Feeds, Ibadan, Nigeria) and allowed unfettered access to drinking water. Animal care and experimental etiquette were executed according to the approved guidelines set by the Redeemer's University Committee on Ethics for Scientific Research. The code for this study was RUN/BCH/17/7121. 
2.6. Experimental design.

Following the duration of acclimatization, the rats were randomly assigned into six groups, each group consisting of six rats. Details of treatment groups consist of the following:

-Group I - control rats received saline once daily.

-Group II- received PmZnONPs (1 mg/kg, p.o) once daily.

-Group III- received PmZnONPs (3 mg/kg, p.o) once daily.

-Group IV- $\mathrm{CCl}_{4}(1 \mathrm{ml} / \mathrm{kg}$, p.o) solution containing olive oil $(1: 1 \mathrm{v} / \mathrm{v})$ once daily.

-Group V- PmZnONPs $(1 \mathrm{mg} / \mathrm{kg}$, p.o $)+\mathrm{CCl}_{4}(1 \mathrm{ml} / \mathrm{kg}$, p.o $)$ once daily.

-Group VI- PmZnONPs (3 mg/kg, p.o) $+\mathrm{CCl}_{4}(1 \mathrm{ml} / \mathrm{kg}$, p.o) once daily.

$\mathrm{CCl}_{4}$ was administered concurrently with PmZnONPs for 7 days, as previously reported [21]. The doses of $1 \mathrm{mg} / \mathrm{kg}$ and $3 \mathrm{mg} / \mathrm{kg}$ PmZnONPs used in this study were based on the suggestion that doses of ZnONPs $(\leq 5 \mathrm{mg} / \mathrm{kg})$ could have beneficial effects in rats [22]. At the end of administration for 7 days, the male Wistar rats were sacrificed after $24 \mathrm{~h}$ of the last treatment via cervical dislocation. After that, the blood was withdrawn via cardiac puncture, centrifuged at $3000 \mathrm{~g}$ for $10 \mathrm{~min}$, and stored at $-20^{\circ} \mathrm{C}$. Subsequently, the liver and kidney tissues were cleaned free of adhering tissues and rinsed with ice-cold $0.25 \mathrm{M}$ sucrose solution, blotted with clean tissue paper, and homogenized in phosphate buffer (0.1 M, pH 7.4). Homogenates were centrifuged at $10,000 \mathrm{~g}$ for $20 \mathrm{~min}$ to obtain the post mitochondrial fraction. The supernatant was collected and used for the various biochemical measurements.

\subsection{Plasma clinical parameters.}

Plasma concentrations of aspartate aminotransferase (AST), alanine aminotransferase (ALT), Alkaline Phosphatase (ALP), Lactate dehydrogenase (LDH), gamma-glutamyl transferase (GGT), albumin, total cholesterol, urea, and creatinine using commercially available diagnostic kits (Randox Lab. Limited) as reported in previous studies. The amount of potassium was determined by a precipitate technique using sodium tetraphenyl boron [23], while the presence of sodium ion was determined as described earlier [24].

\subsection{Assessment of oxidative stress biomarkers.}

Liver and kidney samples from control, $\mathrm{PmZnONPs}$, and $\mathrm{CCl}_{4}$-treated rats were homogenized in $50 \mathrm{mM}$ Tris- $\mathrm{HCl}$ buffer ( $\mathrm{pH} 7.4$ ) containing $1.15 \%$ potassium chloride. The homogenate was subsequently centrifuged at $12,000 \mathrm{~g}$ for $15 \mathrm{~min}$ at $4 \mathrm{oC}$, and the supernatant was used for biochemical assays. Hepatic and renal protein concentration was determined using bovine serum albumin as standard as previously described [25]. Superoxide dismutase (SOD) activity was assayed using epinephrine as the substrate [26], while catalase (CAT) activity was assayed using hydrogen peroxide as the substrate [27]. The levels of reduced glutathione (GSH) and glutathione peroxidase (GPx) were assayed at $412 \mathrm{~nm}$, according to previously described methods [28, 29]. Glutathione-S-transferase (GST) activity was assayed, as reported earlier [30]. Malondialdehyde (MDA) level, an index of lipid peroxidation (LPO), was determined using a previously reported procedure [31].

\subsection{Estimation of inflammatory markers, $C O X-2, I L-6$, and $N F-\kappa B$.}

Hepatic tissues were fixed in neutral formalin solution (10\%) and embedded in paraffin wax before being sectioned (thickness, $5 \mu \mathrm{m}$ ). After deparaffinization of the sections in xylene and rehydration with graded alcohol, antigen retrieval was performed with $10 \mathrm{mM}$ citrate buffer 
at $95-100 \mathrm{oC}$ for $25 \mathrm{~min}$. The peroxidase activity was quenched in 3\% $\mathrm{H} 2 \mathrm{O} 2 /$ methanol solution. The sections were subsequently blocked in goat serum followed by overnight incubation at $4{ }^{\circ} \mathrm{C}$ in the rabbit anti-COX-2, IL-6, and NF- $\kappa$ B primary antibodies (St. John's Laboratory, UK). Subsequently, the slides were washed with tris buffer saline and then incubated with horseradish peroxidase-labeled anti-rabbit monoclonal secondary antibodies. Immune complexes were visualized using $0.05 \%$ 3, 3-diaminobenzidine, and the slides were examined under a light microscope (Leica DM 500, Germany). The images were captured using a digital camera (Leica Biosystems, UK) attached to the microscope. Protein expressions were quantified as integrated optical density as determined by the freely available Image $\mathbf{J}$ software.

\subsection{Statistical analyses.}

Statistical analyses were done using ordinary one-way analysis of variance (ANOVA) to compare the experimental groups followed by Tukey posthoc test using GraphPad Prism 8 software (GraphPad Software, La Jolla, California, USA). Values of $\mathrm{P}<0.05$ were considered significant. The data expression adopted was mean \pm SD $(n=6)$.

\section{Results and Discussion}

\subsection{Characterization of PmZnONPs.}

The FTIR, PS, TEM, SEM, and BET characterizations of PmZnONPS are depicted in Figure 1. The FTIR spectrum of PmZnONPs uncovered absorption bands around 500 - 4000 $\mathrm{cm}^{-1}$ (Figure 1A).
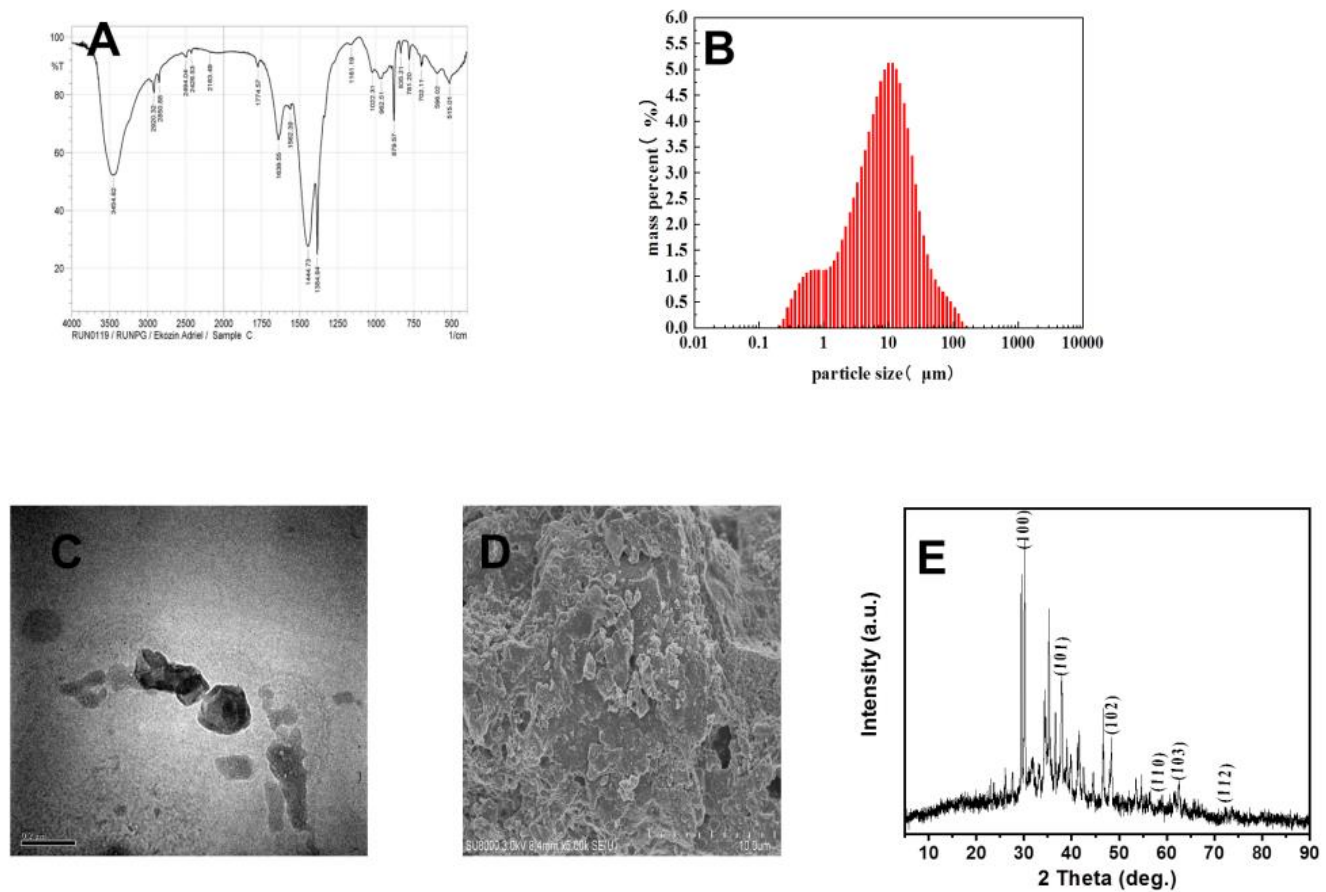

Figure 1. Characterization of Zinc Oxide nanoparticles synthesized from P. mildbraedii (PmZnONPs) (A) FTIR spectra; (B) Particle size distribution; (C) TEM image; (D) SEM pattern; (E) XRD pattern.

PmZnONPS contains Pterocarpus mildbraedii leaf extract. The chemical composition is unknown but contains a mixture of molecules since the extract is from a plant source. However, the vibrational frequencies from the FTIR spectrum suggest the presence of certain 
functional groups from the constituent chemical composition of the Pterocarpus mildbraedii extract that may have contributed to the bio-properties exhibited by PmZnONPs in this study. The peak at $3454.62 \mathrm{~cm}^{-1}$ was attributed to the $\mathrm{O}-\mathrm{H}$ vibrational frequency of alcohol, while peaks at 2920.32 and $2850.88 \mathrm{~cm}^{-1}$ were ascribed to the stretching frequencies of $\mathrm{C}-\mathrm{H}$ of alkane. $\mathrm{C}=\mathrm{O}$ stretch of carbonyl group was seen at 1774.57 and $1639.55 \mathrm{~cm}^{-1}$, while the peaks at 1444.73 and $1384.94 \mathrm{~cm}^{-1}$ were attributed to $-\mathrm{OH}$ bending vibration of alcohol. The peak seen at $1161.19 \mathrm{~cm}^{-1}$ was attributed to the $\mathrm{C}-\mathrm{O}$ stretch, while the peak at $596.02 \mathrm{~cm}^{-1}$ was assigned to the $\mathrm{Zn}-\mathrm{O}$ frequency. The peak observed at $879 \mathrm{~cm}^{-1}$ may be due to the vibrational frequency of $\mathrm{C}=\mathrm{C}$ bending. The particle size is shown in Figure 1B, while the TEM micrograph shown in Figure 1C revealed spherical-like structures with a size of $200 \mathrm{~nm}$. Further micrographs obtained by SEM in Figure 1D showed the particles of PmZnONPs as homogenous and granular. The BET surface area was found to be $1.55 \mathrm{mg}^{-2}$. The XRD of PmZnONPS in Figure $1 \mathrm{E}$ showed the development of hexagonal wurtzite phases, as previously reported [32]. The XRD signal peak of PmZnONPs revealed significant broadening, which may be attributed to its nanoscale size.

\subsection{In vitro antioxidant activities of PmZnONPs.}

Figure 2 shows the DPPH, and ABTS radical scavenging activities of PmZnONPs in comparison with the standard antioxidant, Vitamin $\mathrm{C}$. With an increase in concentrations, the scavenging ability of PmZnONPs against DPPH radical increased, while at the highest concentration $(500 \mu \mathrm{g} / \mathrm{mL})$, PmZnONPs $(77 \%)$ exhibited a similar radical scavenging activity as Vitamin C (84\%). The performance of PmZnONPs against the ABTS radical was similar to that of the DPPH radical. At a concentration of $500 \mu \mathrm{g} / \mathrm{mL}$, PmZnONPs showed a strong ABTS scavenging ability (89\%) comparable to Vitamin C (83\%).

DPPH radical

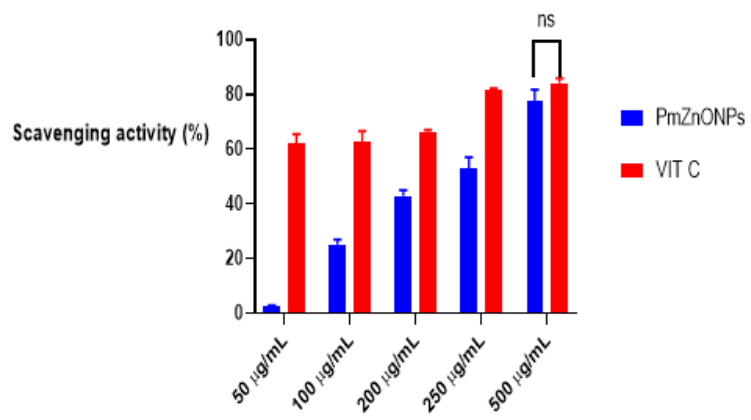

ABTS radical

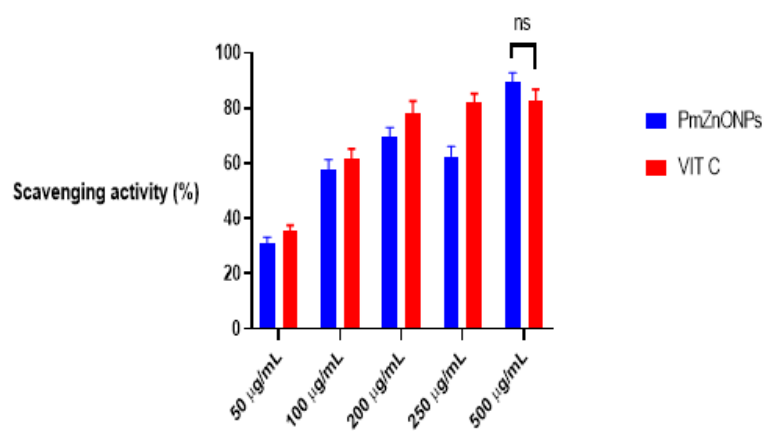

Figure 2. In vitro DPPH and ABTS free radical scavenging activities of Zinc Oxide nanoparticles synthesized from P. mildbraedii (PmZnONPs) in comparison with Vitamin C. Values are represented as Mean $\pm \mathrm{SD}(\mathrm{n}=3$ determinations).

One of the major advantages of green synthesized nanoparticles is the possibility of combining the potency of both nanoparticles and the active ingredients of the plant [33]. In this study, we exploited the pharmacological potential of PmZnONPs. $\mathrm{CCl}_{4}$, an established rodent hepatic- and renal-toxicant, has been reported to amplify oxidative stress due to free radicals generation [34,35]. Consequently, molecules with free-radical scavenging activities could abate toxicities arising from $\mathrm{CCl}_{4}$ intoxication. PmZnONPs showed significant DPPH and ABTS radical scavenging activities comparable to the standard antioxidant, vitamin $\mathrm{C}$. This result is consistent with the free-radical quenching activity reported for Zinc Oxide nanoparticles synthesized from Scutellaria baicalensis [36,37] 
3.3. PmZnONPs ameliorated $\mathrm{CCl}_{4}$-induced impairment of blood chemistry.

The effects of PmZnONPs on clinical blood markers were determined in rats exposed to $\mathrm{CCl}_{4}$ for 7 days (Table 1 ).

Table 1. Effect of PmZnONPS on blood parameters of rats treated with $\mathrm{CCl}_{4}$.

\begin{tabular}{|c|c|c|c|c|c|c|}
\hline & Control & $\begin{array}{l}\text { PmZnONPs } \\
(1 \mathrm{mg} / \mathrm{kg})\end{array}$ & $\begin{array}{l}\text { PmZnONPs } \\
(3 \mathrm{mg} / \mathrm{kg})\end{array}$ & $\mathrm{CCl}_{4}$ & $\begin{array}{l}\text { PmZnONPs } \\
(1 \mathrm{mg} / \mathrm{kg})+\mathrm{CCl}_{4}\end{array}$ & $\begin{array}{l}\mathrm{PmZnONPs} \\
(3 \mathrm{mg} / \mathrm{kg})+\mathrm{CCl}_{4}\end{array}$ \\
\hline ALT (U/L) & $0.27 \pm 0.01$ & $0.27 \pm 0.01$ & $0.27 \pm 0.01$ & $0.31 \pm 0.01^{\mathrm{a}}$ & $0.31 \pm 0.01^{\mathrm{a}}$ & $0.26 \pm 0.02^{\mathrm{b}}$ \\
\hline AST (U/L) & $4.32 \pm 0.19$ & $4.38 \pm 0.16$ & $4.35 \pm 0.01$ & $5.52 \pm 0.01^{\mathrm{a}}$ & $4.67 \pm 0.12^{\mathrm{a}, \mathrm{b}}$ & $4.23 \pm 0.23^{b}$ \\
\hline $\operatorname{ALP}(\mathrm{U} / \mathrm{L})$ & $8.53 \pm 0.67$ & $9.08 \pm 0.90$ & $8.50 \pm 0.67$ & $18.43 \pm 0.67^{\mathrm{a}}$ & $13.48 \pm 0.68^{a, b}$ & $8.53 \pm 0.67^{b}$ \\
\hline GGT (U/L) & $23.55 \pm 0.95$ & $24.32 \pm 0.82$ & $23.39 \pm 0.97$ & $37.83 \pm 0.95^{\mathrm{a}}$ & $27.02 \pm 1.20^{\mathrm{a}, \mathrm{b}}$ & $22.20 \pm 1.54^{b}$ \\
\hline LDH (U/L) & $199.50 \pm 6.03$ & $199.70 \pm 5.18$ & $197.4 \pm 2.26$ & $309.30 \pm 4.40^{\mathrm{a}}$ & $281.50 \pm 9.81^{\mathrm{a}, \mathrm{b}}$ & $189.80 \pm 14.40^{\mathrm{b}}$ \\
\hline $\begin{array}{l}\text { Bilirubin } \\
(\mathrm{mg} / \mathrm{dL})\end{array}$ & $10.54 \pm 0.29$ & $10.50 \pm 0.25$ & $10.91 \pm 0.30$ & $19.02 \pm 0.20^{\mathrm{a}}$ & $18.41 \pm 0.29^{\mathrm{a}, \mathrm{b}}$ & $10.54 \pm 0.18^{\mathrm{b}}$ \\
\hline $\begin{array}{l}\text { Total } \\
\text { Cholesterol } \\
(\mathrm{mg} / \mathrm{dL})\end{array}$ & $124.90 \pm 6.26$ & $134.70 \pm 29.65$ & $126.00 \pm 10.33$ & $248.50 \pm 1.34^{\mathrm{a}}$ & $200.60 \pm 5.58^{\mathrm{a}, \mathrm{b}}$ & $130.20 \pm 12.39^{\mathrm{b}}$ \\
\hline $\begin{array}{l}\text { Albumin } \\
(\mathrm{g} / \mathrm{dL})\end{array}$ & $3.09 \pm 0.07$ & $3.11 \pm 0.09$ & $3.13 \pm 0.08$ & $1.08 \pm 0.04^{\mathrm{a}}$ & $1.62 \pm 0.09^{\mathrm{a}, \mathrm{b}}$ & $3.07 \pm 0 / 03^{b}$ \\
\hline $\begin{array}{l}\text { Creatinine } \\
(\mathrm{mg} / \mathrm{dL})\end{array}$ & $5.20 \pm 0.26$ & $4.99 \pm 15.64$ & $5.09 \pm 0.40$ & $8.81 \pm 0.26^{\mathrm{a}}$ & $5.41 \pm 0.53^{\mathrm{b}}$ & $5.31 \pm 0.33^{\mathrm{b}}$ \\
\hline Urea $(\mathrm{mg} / \mathrm{dL})$ & $60.34 \pm 4.77$ & $60.09 \pm 1.67$ & $59.15 \pm 1.99$ & $89.91 \pm 2.61^{\mathrm{a}}$ & $56.92 \pm 5.04^{b}$ & $59.74 \pm 1.44^{\mathrm{b}}$ \\
\hline $\begin{array}{l}\text { Potassium } \\
(\mathrm{mEq} / \mathrm{L})\end{array}$ & $34.97 \pm 0.42$ & $34.78 \pm 0.26$ & $34.70 \pm 0.14$ & $37.37 \pm 0.35^{\text {a }}$ & $36.08 \pm 0.30^{\mathrm{a}, \mathrm{b}}$ & $35.24 \pm 0.14^{\mathrm{b}}$ \\
\hline $\begin{array}{l}\text { Sodium } \\
(\mathrm{mEq} / \mathrm{L})\end{array}$ & $133.30 \pm 0.30$ & $133.20 \pm 0.21$ & $133.20 \pm 0.29$ & $\begin{array}{l}149.20 \pm 0.18^{\mathrm{a}} \\
133.40 \pm 0.20\end{array}$ & $141.10 \pm 0.34^{\mathrm{a}, \mathrm{b}}$ & $133.40 \pm 0.20^{\mathrm{b}}$ \\
\hline
\end{tabular}

Data are expressed as Mean $\pm \mathrm{SD} ; \mathrm{n}=6$

a indicates $\mathrm{p}<0.05$ when compared with control

$\mathrm{b}$ indicates $\mathrm{p}<0.05$ when compared with $\mathrm{CCl}_{4}$

Data reported herein show that the administration of $\mathrm{CCl}_{4}$ resulted in significant increases $(\mathrm{P}<0.05)$ in hepatic function biomarkers (i.e., ALT, AST, ALP, GGT, LDH, bilirubin, and total cholesterol), renal function indices (i.e., Creatinine and Urea), and electrolytes (i.e., $\mathrm{Na}$ and $\mathrm{K}$ ). Furthermore, $\mathrm{CCl}_{4}$ caused a significant diminution in the levels of albumin. Except for ALT, the treatment of rats with 1 and $3 \mathrm{mg} / \mathrm{kg}$ PmZnONPs resulted in the restoration of these parameters to normal levels.

Typically, liver function tests involve a panel of clinical blood assays, including albumin, bilirubin, and various liver enzymes (alanine aminotransferase (ALT), aspartate aminotransferase (AST), alkaline phosphatase (ALP), $\gamma$-glutamyl transferase, and lactate dehydrogenase. Specifically, a significant presence of these enzymes in the blood is indicative of inflammation or liver injury. PmZnONPS restored $\mathrm{CCl}_{4}$-induced elevation in AST and ALT activities implying its salutary effects on hepatocyte integrity. ALP is ubiquitously found in the liver, bones, intestines, and white blood cells. Hence the British Society of Gastroenterology updated guidelines recommendation of the additional measurement of GGT activity to indicate whether the observed elevation in ALP originated from the liver or other organs [38]. In our study, rises in plasma GGT and ALP activities following $\mathrm{CCl}_{4}$ intoxication were abated by PmZnONPS. However, this result disagrees with an earlier report that showed higher plasma activities of AST, ALT, GGT, ALP, and LDH activities following Zinc oxide nanoparticles administration in rats [39]. The disparity in the two studies may have arisen because Zinc oxide nanoparticles were industrially obtained and fed to rats at the dose of $100 \mathrm{mg} / \mathrm{kg}$ for 75 days, unlike in our study where we used green-synthesized Zinc oxide nanoparticles in combination 
with Pterocarpus mildbraedii leaf extract at a maximum dose of $3 \mathrm{mg} / \mathrm{kg}$. PmZnONPs also restored to near-normal levels the $\mathrm{CCl}_{4}$-induced depletion of albumin and elevations in bilirubin and total cholesterol. An earlier report showed that ZnONPs, synthesized from zinc sulfate and sodium hydroxide, significantly prevented the $\mathrm{CCl}_{4}$-dependent increases in creatinine and urea levels when fed to rats at the dose of $15 \mathrm{mg} / \mathrm{kg}$ for 21 days [40]. In our present study, the nephroprotective effect of PmZnONPs was highlighted by its significant reduction of $\mathrm{CCl}_{4}$-induced increases in creatinine and urea levels. Potassium and sodium are among the essential electrolytes essential for basic physiological processes. High or low levels of electrolytes could complicate adverse outcomes by disorganizing normal bodily functions [41]. In our study, $\mathrm{CCl}_{4}$ significantly elevated $\mathrm{K}^{+}$and $\mathrm{Na}^{+}$levels compared with their respective control groups indicating an underlying kidney malfunction. Fortunately, PmZnONPs reversed these abnormal electrolytes levels towards normal values.

\subsection{PmZnONPs receded hepatorenal oxidative stress associated with $\mathrm{CCl}_{4}$ treatment.}

Afterward, the effects of PmZnONPs on oxidative stress parameters in rats exposed to $\mathrm{CCl}_{4}$ were investigated. In both the liver and the kidney, $\mathrm{CCl}_{4}$ significantly increased catalase activity but reduced SOD and GPx activities. However, treatment with PmZnONPs (1 and 3 $\mathrm{mg} / \mathrm{kg}$ ) restored these antioxidant enzymes to near-normal levels (Figure 3).

Liver: SOD activity

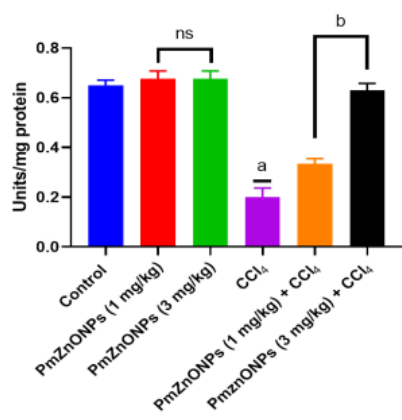

Kidney: SOD activity

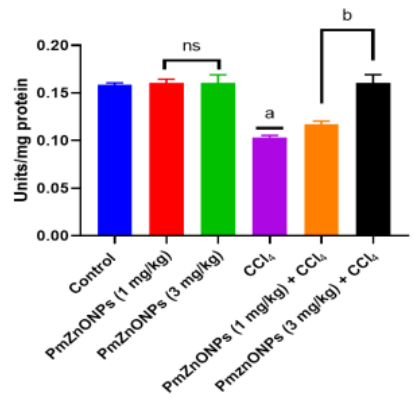

Liver: CAT activity

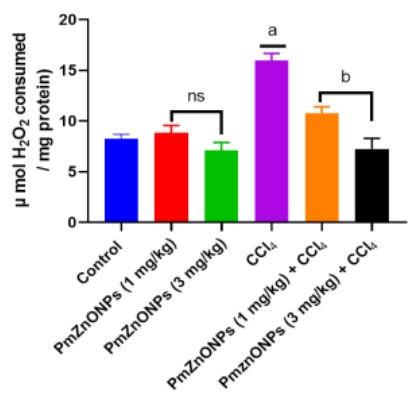

Kidney: CAT activity

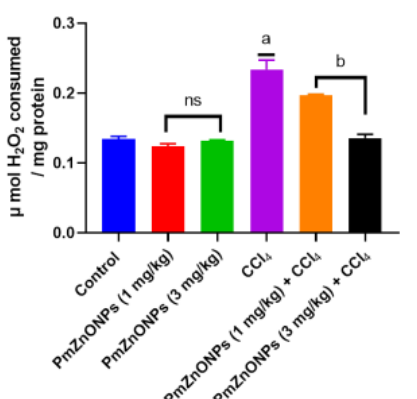

Liver: GPx activity

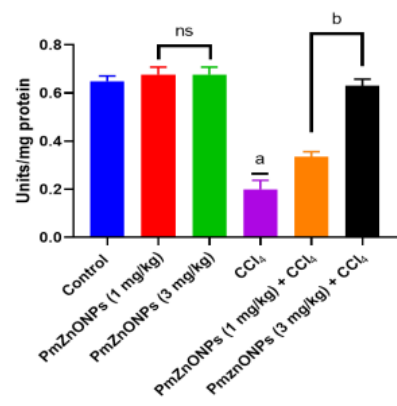

Kidney: GPx activity

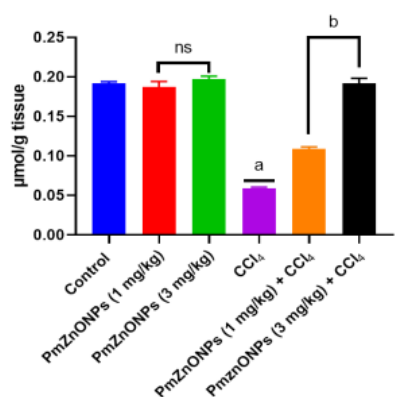

Figure 3. Effect of Zinc Oxide nanoparticles synthesized from P. mildbraedii (PmZnONPs) on antioxidant enzyme activities in the liver and kidney of $\mathrm{CCl}_{4}$-treated rats. Values are expressed as Mean $\pm \mathrm{SD}(\mathrm{n}=6)$. ns not significantly different from control $(\mathrm{p}<0.05)$; a significantly different from control; $\mathrm{b}$ significantly different from Carbon tetrachloride $\left(\mathrm{CCl}_{4}\right)$. $\mathrm{SOD}=$ Superoxide dismutase; $\mathrm{CAT}=$ Catalase; $\mathrm{GPx}=$ Glutathione peroxidase.

Cells have an internal protective mechanism, including the antioxidant defense machinery that preserves cellular oxidative balance by eliminating endogenously generated free radicals or exposure to foreign substances during normal physiological processes. SOD, CAT, and GPX are enzymatic antioxidants that work in tandem to protect against cellular oxidative stress. While SOD dismutases the superoxide anion to hydrogen peroxide, catalase 
or glutathione peroxidase completes the detoxification of hydrogen peroxide to oxygen and water. Hence, the decrease in SOD and GPx activities in rats exposed to $\mathrm{CCl}_{4}$ could result in the build-up of superoxide radicals and hydrogen peroxide in the hepato-renal system [42]. The restoration of SOD and GPx activities confirmed the antioxidant potential of PmZnONPs based on the in vitro free radical scavenging activities.

Also, $\mathrm{CCl}_{4}$ exacerbated oxidative stress in the hepatic and renal organs by depressing GST and GSH levels, with a significant concomitant elevation in LPO. However, oxidative injury to the organs was assuaged by treatment with PmZnONPs ( 1 and $3 \mathrm{mg} / \mathrm{kg}$ ) as indicated by the increase in the antioxidant molecules and the reduction in LPO level in comparison with $\mathrm{CCl}_{4}$-treated animals (Figure 4).

Liver: GST activity

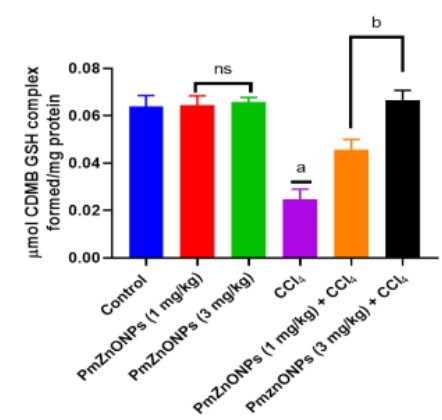

Kidney: GST activity

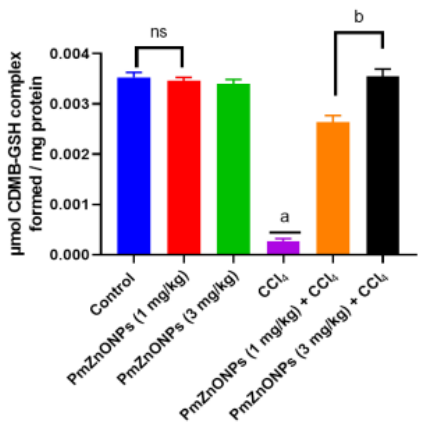

Liver: GSH level

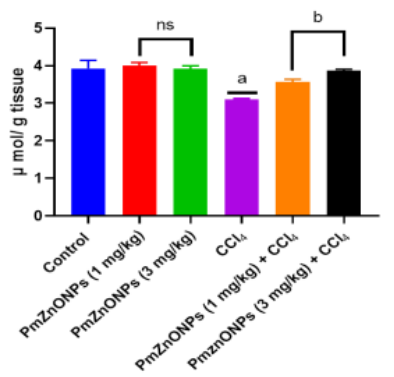

Kidney: GSH level

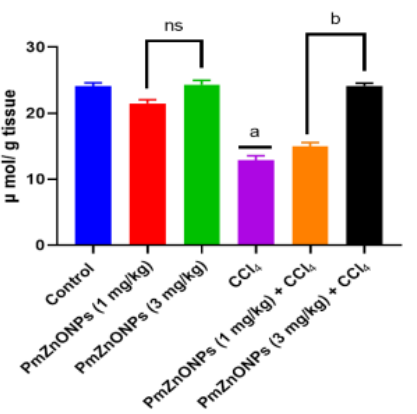

Liver: LPO level

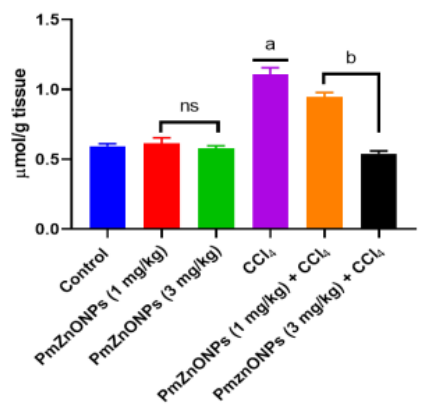

Kidney: LPO level

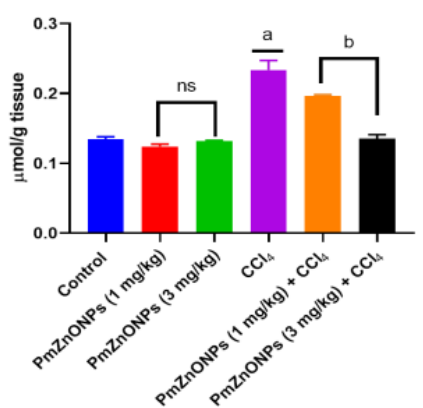

Figure 4. Effect of Zinc Oxide nanoparticles synthesized from P. mildbraedii (PmZnONPs) on GST, GSH, and LPO levels in the liver and kidney of $\mathrm{CCl}_{4}$-treated rats. Values are expressed as Mean $\pm \mathrm{SD}(\mathrm{n}=6)$. ${ }^{\mathrm{ns}}$ not significantly different from control $(\mathrm{p}<0.05)$; ${ }^{\mathrm{a}}$ significantly different from control; ${ }^{\mathrm{b}}$ significantly different from Carbon tetrachloride $\left(\mathrm{CCl}_{4}\right)$. GST $=$ Glutathione $\mathrm{S}$-transferase; $\mathrm{GSH}=$ Reduced glutathione; $\mathrm{LPO}=$ Lipid peroxidation.

The multifarious functions of GST, such as roles in phase II detoxifications, hormone biosynthesis, tyrosine degradation, stress signaling, oxidation-reduction reactions, and posttranslational glutathionylation of proteins, have been documented previously $[43,44]$. The observed increase in GST activity and subsequent depletion of GSH following $\mathrm{CCl}_{4}$ exposure could be due to the increased catalysis of the conjugation reaction between $\mathrm{CCl}_{4}$ and $\mathrm{GSH}$ as part of the cellular protection against free radicals [9]. The restorative effect of PmZnONPs on hepatic and renal GST and GSH levels in rats intoxicated with $\mathrm{CCl}_{4}$ is similar to the ameliorative action of Zinc oxide nanoparticles on antioxidant molecules in a streptozotocinmodel of oxidative stress [10]. Moreover, PmZnONPs' significant reduction of $\mathrm{CCl}_{4}$-mediated increase in LPO further attested to its anti-lipid peroxidative potential. 
$\kappa B$.

The effects of PmZnONPs on COX-2, IL-6, and NF- $\kappa$ B expressions in the liver of rats exposed to $\mathrm{CCl}_{4}$ are shown in Figures 5-7. In the groups treated with $\mathrm{CCl}_{4}$, there were more intense protein immunoreactivities compared with the control group. However, treatment with PmZnONPs significantly attenuated COX-2, IL-6, and NF- $\kappa$ B expressions compared with the $\mathrm{CCl}_{4}$ treatment group.
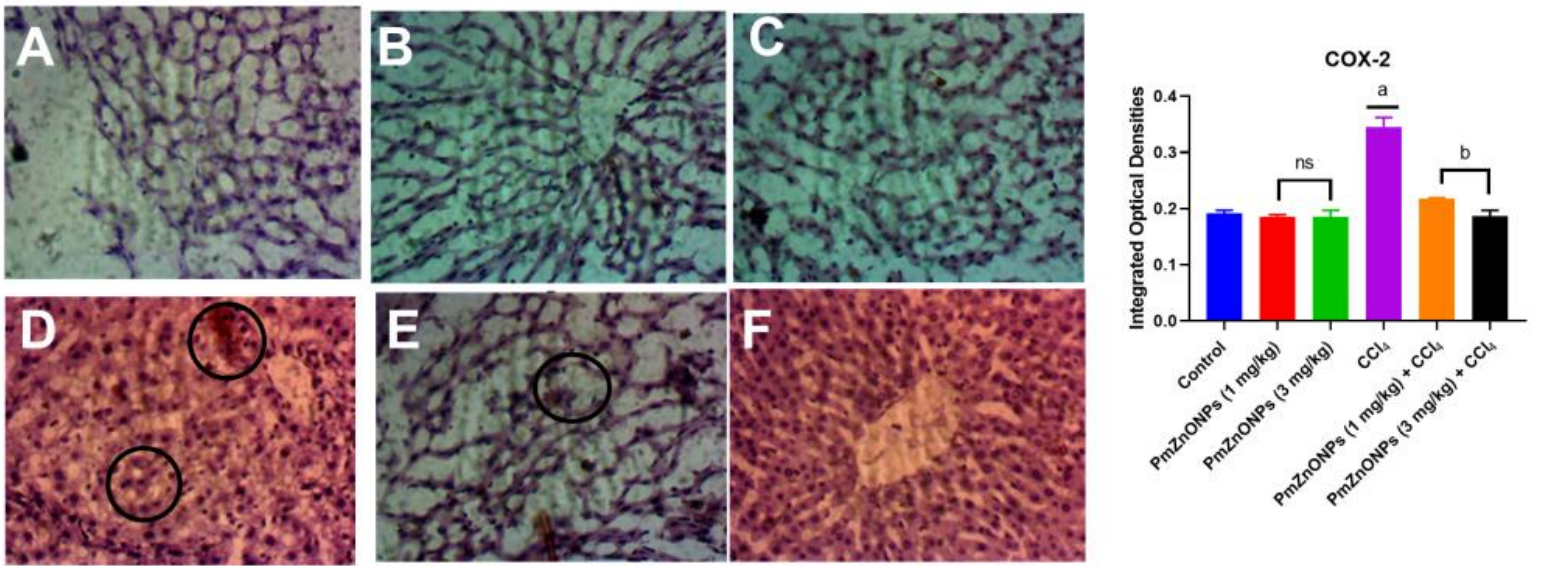

Figure 5. Effect of Zinc Oxide nanoparticles synthesized from $P$. mildbraedii (PmZnONPs) on the immunoreactivity of COX-2 in the liver of CCl4-treated rats. A represents the liver of control rats showing normal COX-2 reactivity. $\mathbf{B}$ and $\mathbf{C}$ represent the liver of rats treated with 1 and $3 \mathrm{mg} / \mathrm{kg}$ PmZnONPs, respectively, showing normal appearing reactivity. $\mathbf{D}$ represents the liver of rats treated with $\mathrm{CCl}_{4}$, while $\mathbf{E}$ and

$\mathbf{F}$ indicate the liver of rats treated with $\mathrm{CCl}_{4}+\mathrm{PmZnONPs}(1 \mathrm{mg} / \mathrm{kg})$ and $\mathrm{CCl}_{4}+\mathrm{PmZnONPs}(3 \mathrm{mg} / \mathrm{kg})$, respectively. Circles indicate regions of enhanced immunoreactivity when compared with the control (X 100 Magnification). Values are expressed as Mean $\pm S D$; ns not significantly different from control $(\mathrm{p}<0.05)$; $\mathbf{a}$ significantly different from control; $\mathbf{b}$ significantly different from Carbon tetrachloride $\left(\mathrm{CCl}_{4}\right)$.
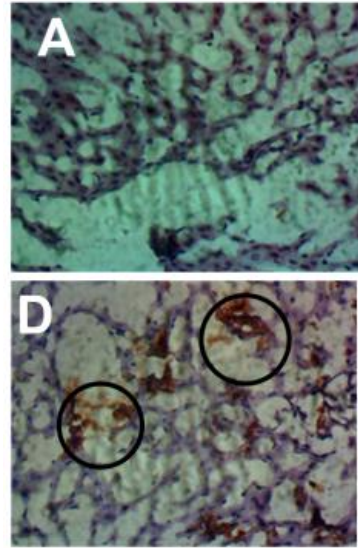
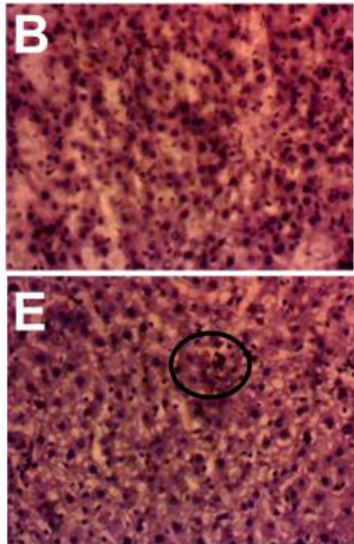
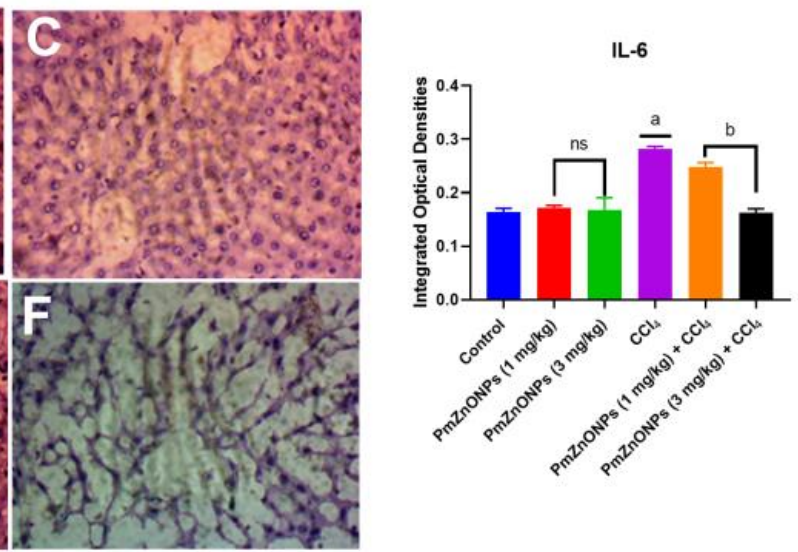

Figure 6. Effect of Zinc Oxide nanoparticles synthesized from P. mildbraedii (PmZnONPs) on the immunoreactivity of IL-6 in the liver of $\mathrm{CCl}_{4}$-treated rats. A represents the liver of control rats showing normal

IL-6 reactivity. $\mathbf{B}$ and $\mathbf{C}$ represent the liver of rats treated with 1 and $3 \mathrm{mg} / \mathrm{kg}$ PmZnONPs, respectively, showing normal appearing reactivity. $\mathbf{D}$ represents the liver of rats treated with $\mathrm{CCl}_{4}$, while $\mathbf{E}$ and $\mathbf{F}$ indicate the liver of rats treated with $\mathrm{CCl}_{4}+\mathrm{PmZnONPs}(1 \mathrm{mg} / \mathrm{kg})$ and $\mathrm{CCl}_{4}+\mathrm{PmZnONPs}(3 \mathrm{mg} / \mathrm{kg})$, respectively. Circles indicate regions of enhanced immunoreactivity when compared with the control (X 100 Magnification). Values are expressed as Mean $\pm \mathrm{SD}$; ns not significantly different from control ( $\mathrm{p}<0.05$ ); a significantly different from control; b significantly different from Carbon tetrachloride $\left(\mathrm{CCl}_{4}\right)$. 

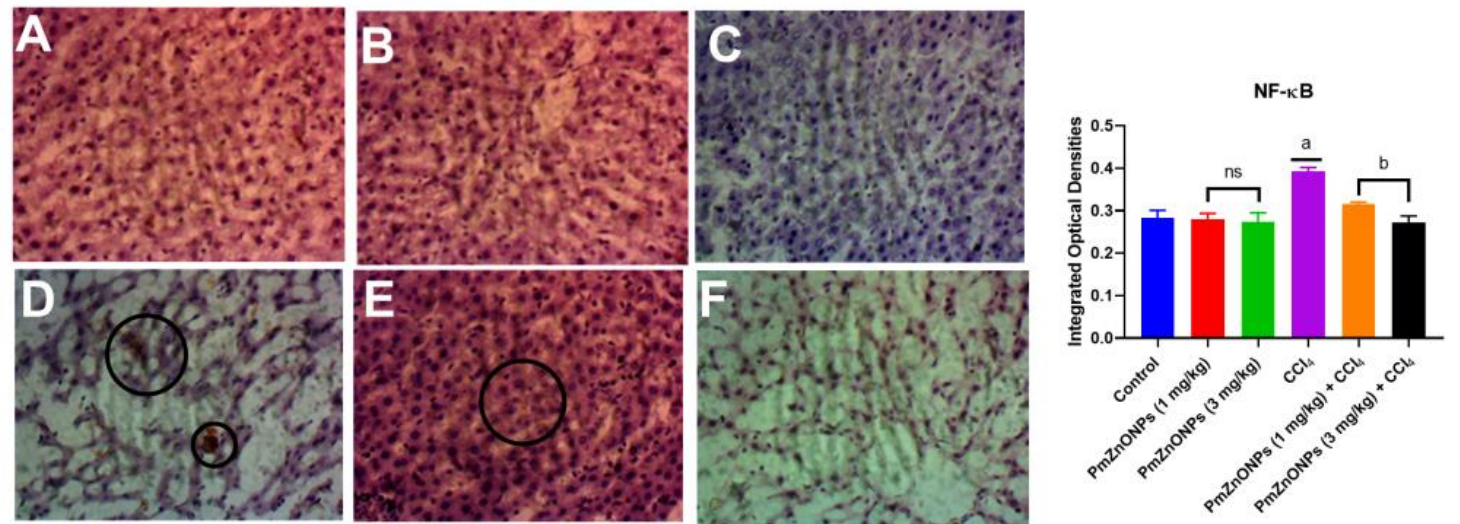

Figure 7. Effect of Zinc Oxide nanoparticles synthesized from P. mildbraedii (PmZnONPs) on the immunoreactivity of $\mathrm{NF}-\kappa \beta$ in the liver of $\mathrm{CCl}_{4}$-treated rats. A represents the liver of control rats showing normal NF- $\kappa \beta$ reactivity. $\mathbf{B}$ and $\mathbf{C}$ represent the liver of rats treated with 1 and $3 \mathrm{mg} / \mathrm{kg}$ PmZnONPs, respectively, showing normal appearing reactivity. $\mathbf{D}$ represents the liver of rats treated with $\mathrm{CCl}_{4}$, while $\mathbf{E}$ and

F indicate the liver of rats treated with $\mathrm{CCl}_{4}+\mathrm{PmZnONPs}(1 \mathrm{mg} / \mathrm{kg})$ and $\mathrm{CCl}_{4}+\mathrm{PmZnONPs}(3 \mathrm{mg} / \mathrm{kg})$, respectively. Circles indicate regions of enhanced immunoreactivity when compared with the control (X 100 Magnification). Values are expressed as Mean \pm SD; ns not significantly different from control $(\mathrm{p}<0.05)$; $\mathbf{a}$ significantly different from control; b significantly different from Carbon tetrachloride $\left(\mathrm{CCl}_{4}\right)$.

$\mathrm{NF}-\kappa \mathrm{B}$ regulates the expression of inflammatory factors, such as Cyclooxygenase- 2 (COX-2) and interleukin-6 (IL-6). Therefore, to establish the link between oxidative damage and inflammation in a $\mathrm{CCl}_{4}$ model of rodent toxicity, we investigated the expressions $\mathrm{NF}-\mathrm{\kappa B}$, COX-2, and IL-6. Previous studies have linked oxidative stress with inflammation following exposure to various agents such as streptozotocin [45], benzo(a) pyrene [42], and isoproterenol [46]. In the present study, the liver of $\mathrm{CCl}_{4}$ - treated rats showed increased immunoreactivities of NF- $\mathrm{B}$, COX-2, and IL-6, suggesting $\mathrm{CCl}_{4}$ induction of inflammation in addition to oxidative stress. However, PmZnONPS elicited significant diminution of NF- $\kappa \mathrm{B}, \mathrm{COX}-2$, and IL-6 immunoreactivities, thus indicating the anti-inflammatory effect of the green synthesized Zinc oxide nanoparticles.

\section{Conclusions}

PmZnONPs ( 1 and $3 \mathrm{mg} / \mathrm{kg}$ ) demonstrated protection against $\mathrm{CCl}_{4}$ - induced oxidative damage and inflammation in the liver and kidney of rats by preserving the clinical blood indices and promoting redox balance. Also, PmZnONPs minimized NF- $\kappa \mathrm{B}, \mathrm{COX}-2$, and IL-6 expressions in rats treated with $\mathrm{CCl}_{4}$. Our results suggest that PmZnONPs possess antioxidant and anti-inflammatory properties that worked synergistically to attenuate $\mathrm{CCl}_{4}$ - induced hepatorenal toxicity.

\section{Funding}

This research received no external funding.

\section{Acknowledgments}

Authors appreciate The TWAS Young Affiliates Network (TYAN) for its contribution to spark the scientific cooperation between AA and FMC. FMC also acknowledges the support received from The Chinese Academy of Sciences (CAS) through the CAS-President's International Fellowship Initiative (PIFI), thereby initiating the collaboration with XF. 


\section{Conflicts of Interest}

The authors declare no conflict of interest. The funders had no role in the design of the study; in the collection, analyses, or interpretation of data; in the writing of the manuscript, or in the decision to publish the results".

\section{References}

1. Latif, A.A.E.; Assar, D.H.; Elkaw, E.M.; Hamza, H.A.; Alkhalifah, D.H.M.; Hozzein, W.N.; Hamouda, R.A. Protective role of Chlorella vulgaris with Thiamine against Paracetamol induced toxic effects on haematological, biochemical, oxidative stress parameters and histopathological changes in Wistar rats. Sci. Rep. 2021, 11, 3911, https://doi.org/10.1038/s41598-021-83316-8.

2. Rismanbaf, A.; Zarei, S. Liver and kidney injuries in COVID-19 and their effects on drug therapy; a Letter to Editor. Archives of Academic Emergency Medicine 2020, 8, e17.

3. Environmental Protection Agency Bulletin. https://www.epa.gov/chemicals-under-tsca. (Accessed on 8th June, 2020).

4. Al Amin, A.S.M.; Menezes, R.G. Carbon Tetrachloride Toxicity. In: StatPearls [Internet]. Treasure Island (FL): StatPearls Publishing 2021, https://www.ncbi.nlm.nih.gov/books/NBK562180/.

5. Kanimozhi, V.; Palanivel, K.; Akbarsha, M.A.; Kadalmani, B. Tributyltin-mediated hepatic, renal and testicular tissue damage in male Syrian hamster (Mesocricetus auratus): a study on impact of oxidative stress. SpringerPlus 2016, 5, 1523, https://doi.org/10.1186/s40064-016-3186-1.

6. Li, R.; Yang, W.; Yin, Y.; Ma, X.; Zhang, P.; Tao, K. 4-OI Attenuates Carbon Tetrachloride-Induced Hepatic Injury via Regulating Oxidative Stress and the Inflammatory Response. Front Pharmacol 2021, 12, 651444. https://doi.org/10.3389/fphar.2021.651444.

7. Mazani, M.; Rezagholizadeh, L.; Shamsi, S.; Mahdavifard,S.; Ojarudi,M.; Salimnejad, R.; Salimi, A. Protection of CCl4-induced hepatic and renal damage by linalool. Drug and Chemical Toxicology 2020, https://doi.org/10.1080/01480545.2020.1792487.

8. Mehendale, H.M. Halogenated Hydrocarbons. Comprehensive Toxicology 2010, 7, 459-474, https://doi.org/10.1016/b978-0-08-046884-6.00824-1.

9. Abolaji, A.O.; Toloyai, P.E.; Odeleye, T.D.; Akinduro, S.; Teixeira Rocha, J. B.; Farombi, E.O. Hepatic and renal toxicological evaluations of an industrial ovotoxic chemical, 4-vinylcyclohexene diepoxide, in both sexes of Wistar rats. Environmental Toxicology and Pharmacology 2016, 45, 28-40, https://doi.org/10.1016/j.etap.2016.05.010.

10. El Naggar, M.; Al-Joufi, F.; Anwar, M.; Attia, M.F.; El-Bana, M.A. Curcumin loaded PLA-PEG copolymer nanoparticles for treatment of liver inflammation in streptozotocin-induced diabetic rats. Colloids and Surfaces B: Biointerfaces 2019, 177, 389-398, https://doi.org/10.1016/j.colsurfb.2019.02.024.

11. Alsubki, R.; Tabassum, H.; Abudawood, M.; Rabaan, A.A.; Alsobaie, S.F.; Ansar, S. Green synthesis, characterization, enhanced functionality and biological evaluation of silver nanoparticles based on Coriander sativum. Saudi J Biol Sci. 2021, 28, 2102-2108, https://doi.org/10.1016/j.sjbs.2020.12.055.

12. Otuechere, C.A.; Adewuyi, A.; Adebayo, O.L.; Ebigwei, I.A. In vivo hepatotoxicity of chemically modified nanocellulose in rats. Hum Exp Toxicol. 2020, 39, 212-223, https://doi.org/10.1177/0960327119881672.

13. Otuechere, C.A.; Adewuyi, A.; Oluwabayo, T.; Afolayan, F.; Avwioroko, O.; Abazuh, U. Salubrious effects of a vermiculite-cellulose-based bionanocomposite on oxidative stress indices and histomorphology of male Wistar rats. Andrologia, 2020, 52, e13426, https://doi.org/10.1111/and.13426.

14. Umavathi, S.; Mahboob, S.; Govindarajan, M.; Al-Ghanim, K.A.; Ahmed, Z.; Virik, P.; Al-Mulhm, N.; Subash, M.; Gopinath, K.; Kavitha, C. Green synthesis of $\mathrm{ZnO}$ nanoparticles for antimicrobial and vegetative growth applications: A novel approach for advancing efficient high quality health care to human wellbeing. Saudi J Biol Sci. 2021, 28, 1808-1815, https://doi.org/10.1016/j.sjbs.2020.12.025.

15. Amuthavalli, P.; Hwang, J.S.; Dahms, H.U.; Wang, L.; Anitha, J.; Vasanthakumaran, M.; Gandhi, A.D.; Murugan K, Subramaniam, J.; Paulpandi, M.; Chandramohan, B.; Singh, S. Zinc oxide nanoparticles using plant Lawsonia inermis and their mosquitocidal, antimicrobial, anticancer applications showing moderate side effects. Sci Rep. 2021, 11, 8837, https://doi.org/10.1038/s41598-021-88164-0.

16. Selim, Y.A.; Azb, M.A.; Ragab, I.H.M.; Abd El-Azim, M. Green synthesis of Zinc oxide nanoparticles using aqueous extract of Deverra tortuosa and their cytotoxic activities. Sci Rep 2020, 10, 3445, https://doi.org/10.1038/s41598-020-60541-1.

https://biointerfaceresearch.com/ 
17. Otuechere, C.A.; Farombi, E.O. Pterocarpus mildbraedii leaf extract ebbs propanil-induced oxidative and apoptotic damage in the liver of rats. Drug Chem Toxicol. 2020, 4, 1-8, https://doi.org/10.1080/01480545.2020.1842884.

18. Otuechere, C.A.; Farombi, E.O. Pterocarpus mildbraedii (Harms) extract resolves propanil-induced hepatic injury via repression of inflammatory stress responses in Wistar rats. J Food Biochem. 2020, 44, e13506, https://doi.org/10.1111/jfbc.13506.

19. Otuechere, C.A.; Farombi, E.O. Comparative studies on the antioxidant and scavenging activities of Garcinia kola extract and vitamin E: Modulatory effects on $\mathrm{KBrO} 3$ - induced oxidative stress in rats. Journal of Chemical and Pharmaceutical Research 2012, 4, 3676-3683.

20. Atolani, O.; Oguntoye, H.; Areh, E.T.; Adeyemi, O.S.; Kambizi, L. Chemical composition, anti-toxoplasma, cytotoxicity, antioxidant, and anti-inflammatory potentials of Cola gigantea seed oil. Pharmaceutical Biology 2019, 57, 154-160, https://doi.org/10.1080/13880209.2019.1577468.

21. Owojuyigbe, O.S.; Larbie, C.; Firempong, C.; Komlaga, G.; Emikpe, B.; Otuechere, C. A. Extracts of Hura crepitans L. stem bark attenuate liver injury and inflammation induced by CCl4 in rats. Comp Clin Pathol 2020, https://doi.org/10.1007/s00580-020-03172-2.

22. El-Maddawy, Z.K.; Abd El Naby. W. S. H.; Protective effects of zinc oxide nanoparticles against doxorubicin induced testicular toxicity and DNA damage in male rats. Toxicology Research 2019, 8, 654662, https://doi.org/10.1039/c9tx00052f.

23. Terri, A.E.; Sesin, P.G.; Determination of serum potassium by using sodium tetraphenylboro method. Am. J. Clin. Path. 1958, 29, 86-90, https://doi.org/10.1093/ajcp/29.1_ts.86.

24. Pramina, K.V.; Mincy, P.T.; Joseph, P.A.; Lisha, V.; Mercy, K.A.; Ramnath, V. Levels of calcium, sodium and potassium in plasma as influenced by anticoagulants. J Vet Anim Sci. 2013, 44, 72-75.

25. Bradford, M. A rapid and sensitive method for the quantitation of microgram quantities of protein utilizing the principle of protein-dye binding. Analytical Biochemistry 1976, 72, 248-254, https://doi.org/10.1016/0003-2697(76)90527-3.

26. Misra, H.P.; Fridovich, L. The role of superoxide anion in the autooxidation of epinephrine and a simple assay for superoxide dismutase. J. Biol. Chem. 1972, 247, 3170-3175.

27. Clairborne, A.; Catalase activity, in: A.R. Greewald (Ed.). Handbook of methods for oxygen radical research. CRC Press, Boca Raton, FL 1985, 283-282.

28. Beutler, E.; Duron, O.; Kelly, B.M. Improved method for the determination of blood glutathione. J Lab Clin Med 1963, 61, 882-888.

29. Rotruck, J.T.; Pope, A.L.; Ganther, H.E.; Swanson, A.B.; Hafeman, D.G.; Hoekstra, W.G. Selenium: Biochemical Role as a Component of Glutathione Peroxidase. Science 1973, 179, 588-590, https://doi.org/10.1126/science.179.4073.588.

30. Habig, W.H.; Pabst, M.J.; Jakoby, W.B. Glutathione S-transferase. The first enzymatic step in mercapturic acid formation. J Biol Chem 1974, 249, 7130-7139.

31. Adewuyi, A.; Otuechere, C.A.; Adebayo, O.L.; Ajisodun, I. Synthesis and toxicity profiling of sebacic acidmodified cellulose from unexploited watermelon exocarp. Polym. Bull. 2021, 78, 1149-1173, https://doi.org/10.1007/s00289-020-03152-0.

32. Ramirez-Vick, J.; Rodriguez-Martinez, C.; Joshi, P.; Vera, J.; Perales, O.; Singh, S. Cytotoxic studies of PEG functionalized ZnO nanoparticles on MCF-7 cancer cells. NSTI Nanotechnol Conf Expo 2011, 3, 420423.

33. Ahmed, R.H.; Mustafa, D.E. Green synthesis of silver nanoparticles mediated by traditionally used medicinal plants in Sudan. Int Nano Lett 2020, 10, 1-14, https://doi.org/10.1007/s40089-019-00291-9.

34. El-Bialy, B.; El-Boraey, N.G.; Hamouda, R.A.; Abdel-Daim, M.M. Comparative protective effects of spirulina and spirulina supplemented with thiamine against subacute Carbon tetrachloride toxicity in rats. Biomed Pharmacol J 2019, 12, 511-525, https://dx.doi.org/10.13005/bpj/1670.

35. Rahmouni, F.; Badraoui, R.; Amri, N.; Elleuch, A.; El-Feki, A.; Rebai, T.; Saoudi, M. Hepatotoxicity and nephrotoxicity in rats induced by Carbon tetrachloride and the protective effects of Teucrium polium and vitamin C. Toxicology Mechanisms and Methods 2019, 29, 313-321, https://doi.org/10.1080/15376516.2018.1519864.

36. Soren, S.; Kumar, S.; Mishra, S.; Jena, P.K.; Verma, S.K.; Parhi, P. Evaluation of antibacterial and antioxidant potential of the zinc oxide nanoparticles synthesized by aqueous and polyol method. Microbial Pathogenesis 2018, 119, 145-151, https://doi.org/10.1016/j.micpath.2018.03.048. 
37. Tettey, C.O.; Shin, H.M. Evaluation of the antioxidant and cytotoxic activities of zinc oxide nanoparticles synthesized using Scutellaria baicalensis root. Scientific African 2019, 6, e00157, https://doi.org/10.1016/j.sciaf.2019.e00157.

38. Newsome, P.N.; Cramb, R.; Davison, S.M.; Dillon, J.F.; Foulerton, M.; Godfrey, E.M.; Hall, R.; Harrower, U.; Hudson, M.; Langford, A.; Mackie, A.; Mitchell-Thain, R.; Sennett, K.; Sheron, N.C.; Verne, J.; Walmsley, M.; Yeoman, A. Guidelines on the management of abnormal liver blood tests. Gut 2018, 67, 619, https://doi.org/10.1136/gutjnl-2017-314924.

39. Yousef, M.I.; Mutar, T.F.; Kamel, M. Hepato-renal toxicity of oral sub-chronic exposure to aluminum oxide and/or zinc oxide nanoparticles in rats. Toxicology Reports 2019, 6, 336-346, https://doi.org/10.1016/j.toxrep.2019.04.003.

40. Hussain, Z.; Khan, J.A.; Anwar, H.; Andleeb, N.; Murtaza, S.; Ashar, A.; Arif, I. Synthesis, characterization, and pharmacological evaluation of zinc oxide nanoparticles formulation. Toxicology and Industrial Health 2018, 34, 753-763, https://doi.org/10.1177/0748233718793508.

41. Shrimanker, I.; Bhattarai, S. Electrolytes. In: StatPearls. StatPearls Publishing, Treasure Island (FL) 2019.

42. Ajayi, B.O.; Adedara, I.A.; Farombi, E.O. 6-Gingerol abates benzo[a] pyrene-induced colonic injury via suppression of oxido-inflammatory stress responses in BALB/c mice. Chemico-Biological Interactions 2019, 307, 1-7, https://doi.org/10.1016/j.cbi.2019.04.026.

43. Kumar, S.; Prabodh, T. Glutathione S-Transferases: Role in combating abiotic stresses including arsenic detoxification in plants. Frontiers in Plant Science 2018, 9, 751, https://doi.org/10.3389/fpls.2018.00751.

44. Llavanera, M.; Mateo-Otero, Y.; Bonet, S.; Barranco, I.; Fernández-Fuertes, B.; Yeste, M. The triple role of glutathione S-transferases in mammalian male fertility. Cell Mol Life Sci 2020, 77, 2331-2342, https://doi.org/10.1007/s00018-019-03405-w.

45. Wang, X.; Li, C.; Huan, Y.; Cao, H.; Sun, S.; Lei, L.; Liu, Q.; Liu, S.; Ji, W.; Huang, K.; Shen, Z.; Zhou, J. Diphenyl diselenide ameliorates diabetic nephropathy in streptozotocin-induced diabetic rats via suppressing oxidative stress and inflammation. Chem Biol Interact 2021, 338, 109427 , https://doi.org/10.1016/j.cbi.2021.109427.

46. Bei, W.; Jing, L.; Chen, N. Cardio protective role of wogonin loaded nanoparticle against isoproterenol induced myocardial infarction by moderating oxidative stress and inflammation. Colloids Surf B Biointerfaces 2020, 185, 110635, https://doi.org/10.1016/j.colsurfb.2019.110635. 